\title{
School-related factors contributing to the delivery enhancement of the special science program in Western Visayas, Philippines
}

\author{
Porferio S. Bangcaya ${ }^{1}$, Grecebio Jonathan D. Alejandro²* \\ ${ }^{1}$ College of Teacher Education, Biological Science Department, University of Antique, Tibiao Campus, 5707 Antique, \\ Philippines. \\ ${ }^{2}$ College of Science and The Graduate School, University of Santo Tomas, Espana, 1015, Manila, Philippines. \\ For correspondence: gdalejandro@mnl.ust.edu.ph
}

\begin{abstract}
:
In this mixed-method study, the secondary schools in Western Visayas, Philippines offering special science program (SSP) were assessed as basis for delivery enhancement. The SSP along student-related factors and the extent of implementation in the areas of curriculum and instruction, laboratory facilities, and administration in terms of the different classification of Philippines' Department of Education (DepED) were evaluated. A survey instrument was used to gather information from the principals, department heads, science and mathematics teachers handling special science classes, property or laboratory custodians representing nine participating special science classes (SSC) in Western Visayas. Descriptive analysis was done using percentage, mean and standard deviation shown in graphs and tables. Results of the study revealed that the National Achievement Test mean percentage score of the students for the last three years had an irregular trend and majority of students' participation in science-related activities was in the regional level. There was a high extent of implementation along the areas of curriculum and instruction and administrative support. The common problem encountered by teachers was the lack of laboratory facilities that were described insufficient while the library resources were sufficient.
\end{abstract}

Keywords: special science program, delivery enhancement, national achievement test, curriculum and instruction, laboratory facilities

\section{Introduction}

Evaluation and assessment are vital components of every school program because it conveys the stakeholders whether such is successful or a failure. According to Calderon and Gonzales (1993), evaluation is a process of determining the quality of worth of achievement in terms of certain standards. Thus, it becomes a systematic procedure of determining the quality of the result of the measurement with the end in view of improving and maximizing the acquisition of educational outcomes such as knowledge, skills, attitudes and habits. On the other hand, assessment indicates a wide selection of methods that educators use to evaluate, measure, and document the academic development of students in several aspects (The glossary of education reforms, 2013).

Assessment of students is directed toward measuring their competence. Specifically, this process measures their progress toward attaining those competencies from their schools or parents want them to master. High quality assessment procedures take into consideration the fact that the students' performance on any task is influenced by the demands of the task itself, by the history and characteristics they bring to the task, and by the factors inherent in the context in which assessment is carried out (Silva and Ysseldyke, 1998).

A very important educational endeavour is the assessment of teacher's performance. Its relevance in the context of school accountability on the learning of students cannot be underestimated (David and Macayan, 2010). Accountability is a top priority in any educational programs and assessments to measure the effectiveness of teachers. 
Furthermore, there are many factors contributing to effective classroom instruction and the teacher is recognized as the greatest influence on the program's success (Shymansky, 1978). Hence, the assessment of teachers' performance should be a major concern of educational institution to determine how teachers perform their roles as facilitators of learning inside the classroom. Teachers performance can be interpreted into students ${ }^{\prime}$ learning achievement and their progress towards the desired skills and abilities (David and Macayan, 2010).

The Philippines' Department of Education (DepED) continues to evaluate the effectiveness of the curricula used for elementary and high school to improve the quality of education in the Philippines. In high school, a series of development has been done for the improvement of the quality of science education in the Philippines. Several revisions have been made in the curriculum by enhancing the mode of instruction, along with revitalizing its content to reflect current trends and improved cultural relevance. A linkage is another managerial function that includes external communications and activities that provide support to the school programs and goals. According to Gray (1990), connections among schools, industry, and the community, both foreign and domestic, are very crucial to research, education and competitiveness.

Likewise, a supportive environment is critical to the work performance in any system. The presence of organizational support and resources may be much more critical for teachers, considering that they are presented with challenges in dealing with a number of difficult tasks of making the students learn (Yoon and Gilchrist, 2003). Yoon \& Gilchrist (2003) further showed that lack of administrative support has been linked consistently to stress and poor teachers' performance. In the same manner, Fuller (1987) also noted that the presence of laboratories raised science achievement in secondary schools in India and primary schools in Thailand, Iran and Brazil.

The DepED aims to provide an education that is humanistic in spirit, global in perspective, and patriotic in orientation; thus, envisions to produce technologically and globally competitive graduates. This resulted in the implementation of a special science class curriculum for advanced and scientifically inclined students. This is also a way to answer the demands of science-related courses in the country.

The Science and Technology Education (STE) program, formerly Engineering and Science Education Project (ESEP) of the DepED, was recognized by the Department of Science and Technology (DOST). The revised curriculum of the Engineering and Science Education Project (ESEP) of Science and Technology (S\&T) - oriented high schools (DepED) Order No. 41.s.2004 enhanced the core subjects offered in the 2010 secondary education curriculum.

While students of special science classes (SSC) perform very well in national entrance examinations in the different colleges and universities in the Region, there has been no scientific assessment of how well the special science programs (SSP) are delivered. It is the objective of this study to take a comprehensive assessment of how well the different components or areas of the SSP are being delivered. Specifically, this paper determines the profile of the student of the SSP in Western Visayas in terms of National Achievement Test (NAT) mean percentage score and participation in science related activities; and the extent of implementation of the SSP in Western Visayas along the areas of curriculum and instruction, laboratory facilities, and administration in terms of DepED classification as Type A, Type B, and Type C and further classified as DOST-ESEP-Old, DOST-ESEP-New, and NonDOST-ESEP-Existing.

\section{Methodology}

\section{Participants}

Participants of the study were the department heads, science and mathematics teachers, librarians, and laboratory custodians of the nine participating SSC in Western Visayas. The SSC was categorized into class A (old) with DOST-SEI support, class B (new) with DOST-SEI support, and class C (existing) without DOST-SEI support. 


\section{Instruments}

This study utilized a survey instrument. To assess the inputs of the SSPs, two sets of questionnaires were utilized. First is the student-related factors to measure the student-related inputs of the SSPs included their NAT mean percentage scores taken from the students' profile available in the principals office, and participation in science-related activities supplied by the science and mathematics teachers. Second are the school-related factors to assess the extent of administrative support and curriculum and instruction. The teachers were asked to respond on the extent of administrative support given to them and the curriculum and instruction offered by the DepED on the following basis: very high extent of implementation, low extent of implementation, and very low extent of implementation.

\section{Methods}

A descriptive method of research was utilized in this study. A survey was employed purposively among the participants. The survey instruments were distributed to purposively chosen informants in SSC of Western Visayas. The instrument was personally distributed; thus, explicit instructions were verbally given on how to administer the instrument and a reminder note was attached to the given form. The accomplished survey forms were gathered a week after distribution from the informants through their principal. To accommodate the returned form, a properly labeled box was placed in the office of the principal for the informants to drop their forms. This was also done to ensure that the informants could return their forms even if the principal was not around.

\section{Data Analysis}

The different sets of data were analyzed according to the requirements of the research problems using appropriate statistical treatment. The mean and the standard deviation were utilized to obtain the average scores of the curriculum and instruction, administrative support and availability of the laboratory facilities. Frequency counts were utilized to determine the participation in science-related activities. Data were processed using the Statistical Package for the Social Sciences (SPSS) software v. 19.

The following scale and corresponding descriptions were used in the interpretation of data:

For the extent of implementation along the area of curriculum and instruction.

$\begin{array}{lll}\text { Scale } & \text { Description } & \text { Interpretation } \\ 3.51-4.00 & \text { Very High } & \text { Curriculum is fully implemented } \\ 2.51-3.50 & \text { High } & \text { Curriculum is highly implemented } \\ 1.51-2.50 & \text { Low } & \text { Curriculum is slightly implemented } \\ 1.00-1.50 & \text { Very Low } & \text { Curriculum is not implemented }\end{array}$

For the extent of implementation along the area of administrative support.

\begin{tabular}{|c|c|c|}
\hline Scale & Description & Interpretation \\
\hline $3.51-4.00$ & Very High & $\begin{array}{c}\text { Teachers are fully supported by } \\
\text { Administrators }\end{array}$ \\
\hline 2.51-3.50 & High & $\begin{array}{c}\text { Teachers are highly supported by } \\
\text { Administrators }\end{array}$ \\
\hline $1.51-2.50$ & Low & $\begin{array}{c}\text { Teachers are slightly supported by } \\
\text { Administrators }\end{array}$ \\
\hline $1.00-1.50$ & Very Low & $\begin{array}{c}\text { Teachers are not supported by } \\
\text { Administrators }\end{array}$ \\
\hline
\end{tabular}




\section{Results and Discussion}

\section{Student-related Factors}

Students-related factors included in this study were the mean percentage scores of the students in the NAT which is a standardized test administered by the Department of Education National Educational Testing and Research Center (NETRC), and the number of science-related activities engaged in by the students. The data give a good picture of the performance of the students in the delivery of the SSC program and the entire school with the concerted efforts of the principal, department head, faculty members, as well as non-teaching personnel.

The NAT is an annual examination given to both Grades nine and ten students in the Philippines. The students' knowledge and mastery of the subjects such as Mathematics, Science and Filipino are measured using a multiple-choice type of test. In this study, only science and mathematics results were used to determine the Students' performance along the national standardized test. On the other hand, the NAT mean percentage score (MPS) measures the student's proficiency which can be attributed to the teachers' dedication and commitment to the teaching profession and the school itself, especially giving focus on the academic achievement of their students.

Result shows that the mean percentage scores of students reflect a relatively low performance across various school types covering a period of three school years with a range of only 45-71.9\% (Figure 1). Nevertheless, students from Type A schools performed relatively better than those from other school types. However, it is surprising to note that students in Type A schools showed a decreased trend from 71.9 to $66.9 \%$, while that in other school types it was fluctuating (Type B) or relatively constant (Type C) although far lower. This finding needs to be further investigated to determine the reasons behind such a trend. Likewise, the result for Type A schools for SY 2012-2013 does not appear because the results released by the NETRC were for the entire school.

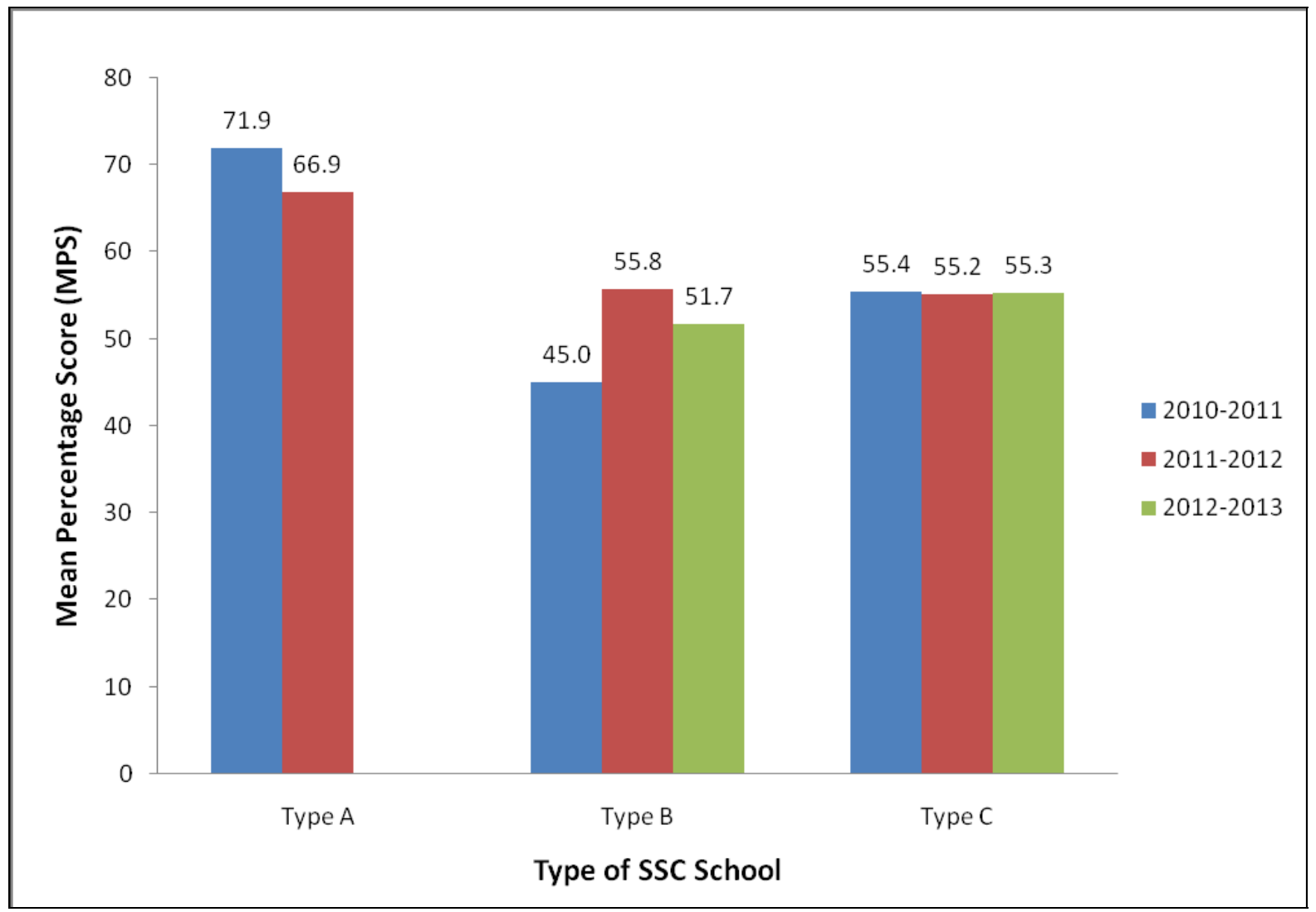

Figure 1. Mean percentage scores (MPS) of students in the National Achievement Test among participating schools 
As cited by Hamilton (2014), student activities support the academic mission of the school by working to create experiential learning options outside of the classroom and encouraging students to actively participate in the greater educational community. Basically, students' participation in activities does not only provide fun but a learning experienced as well to develop their leadership skills and responsibilities. Activities displayed in this study are designed by the DepED to enrich the knowledge and skills of the students and the teachers who are considered the core of excellence of the department. These activities are performed for the SSC in the region.

Results revealed that among the various types of SSC schools evaluated, Type A Schools had the most number of engagements in science-related activities at 217 compared with 117 and 101 only for Types B and C, respectively (Figure 2). Students in Type A schools had more number of activities across various types, such as research competition, seminar/training workshop, symposium, science camp, and quiz bowl. The large difference among Type $\mathrm{A}$ and Types $\mathrm{B}$ and $\mathrm{C}$ may be attributed to the linkages of the school, financial capabilities, proximity to venues, and support from local administrators, among other factors. Thus, it is important that such factors be accorded to Types B and $\mathrm{C}$ schools to ensure that their students are given equal opportunities as well.

The present findings is supported by Astin (1993) that almost any type of student involvement in college positively affects student learning and development. Extracurricular activities provide a setting to become involved and to interact with other students, thus leading to increased learning and enhanced development. Likewise, National Association of Secondary School Principals (NASSP, 2009) research suggests that, participation in student activities is associated with higher test scores increased GPA, enhanced civic skills, better future job practices, lower drop-out rates, and lower incidence of adolescence behaviours.

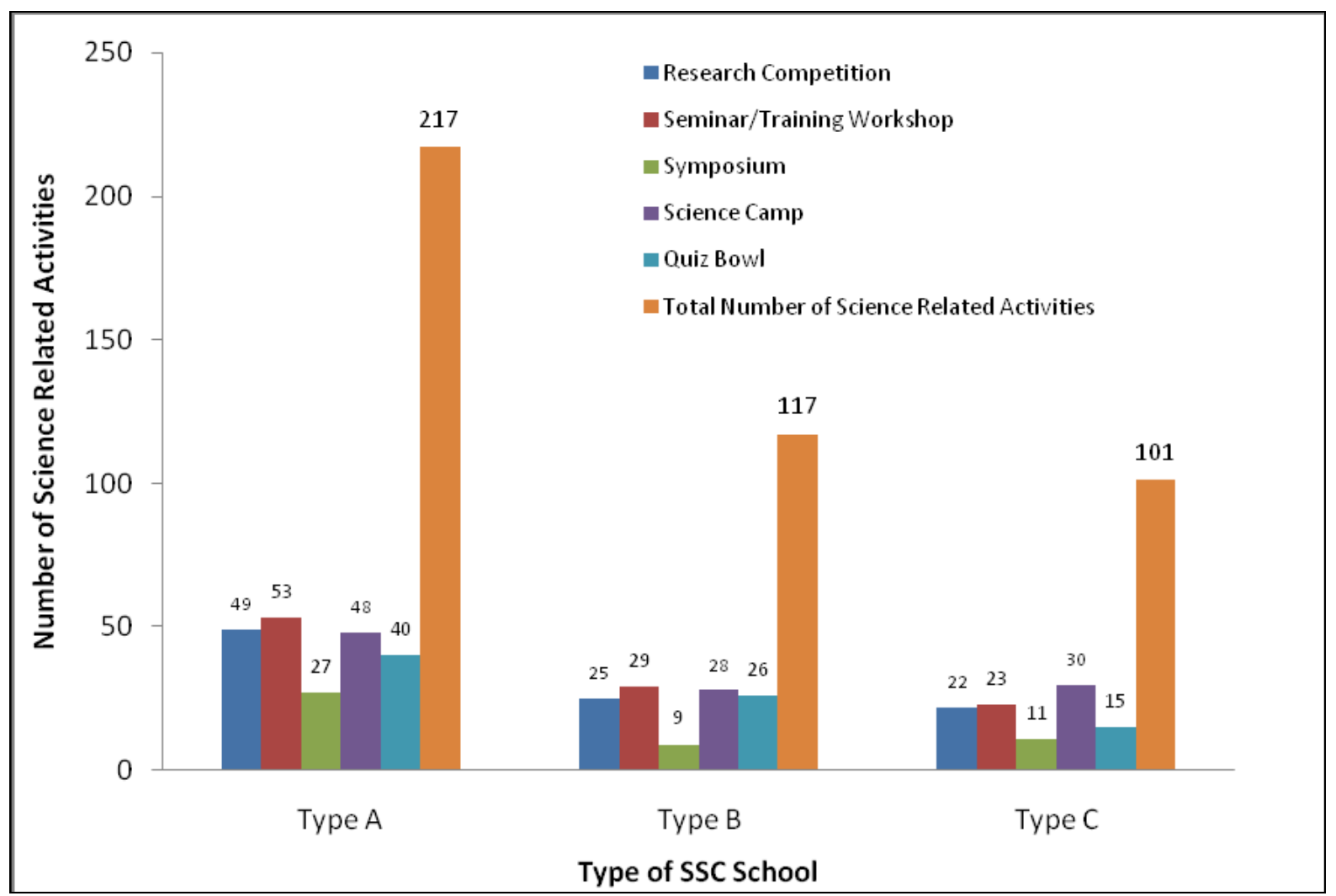

Figure 2. Total number of science-related activities engaged in by students in participating schools 
Extent of implementation of the Special Science Program in Western Visayas: Curriculum and Instruction and Administrative Support

The data on the extent of implementation of the SSP along the areas of curriculum and instruction together with the administrative support as perceived by the SSC teachers give a good picture that they are satisfied with the curriculum as well as the support coming from the administration. Curriculum and instruction along this line were categorized into four: instructional resources, teachers' competencies, evaluation and grading system, and learning styles and techniques. The administrative support was grouped as to faculty development, instructional leadership, resources, and the rules, policies, and admission requirements. They were assessed by looking into the mean scores computed from their answers in the instruments.

The extent of implementation of the SSP in Western Visayas along the areas of curriculum and instruction by classification was compared among participating schools in this survey. In general, it was observed that there was a very high extent of implementation across school types (Table 1). This very high extent of implementation suggests that all concerned parties have followed all recommendations and guidelines set forth by the Department of Education for schools with SSC.

Table 1. Extent of implementation of special science program (SSP) in Western Visayas along the areas of curriculum and instruction.

\begin{tabular}{|c|c|c|c|}
\hline \multicolumn{2}{|l|}{ Type of School } & Mean & Description \\
\hline \multicolumn{2}{|c|}{ A. Entire Group } & 4.00 & Very High \\
\hline \multicolumn{4}{|c|}{ B. Type A Schools - DOST-ESEP (Old) } \\
\hline \multicolumn{2}{|c|}{ Instructional Resources } & 4.00 & Very High \\
\hline \multicolumn{2}{|c|}{ Teachers Competencies } & 4.00 & Very High \\
\hline \multicolumn{2}{|c|}{ Evaluation and Grading System } & 4.00 & Very High \\
\hline \multicolumn{2}{|c|}{ Learning Styles and Techniques } & 4.00 & Very High \\
\hline C. 1 & -ESEP (New) & & \\
\hline \multicolumn{2}{|c|}{ Instructional Resources } & 4.00 & Very High \\
\hline \multicolumn{2}{|c|}{ Teachers Competencies } & 4.00 & Very High \\
\hline \multicolumn{2}{|c|}{ Evaluation and Grading System } & 4.00 & Very High \\
\hline \multicolumn{2}{|c|}{ Learning Styles and Techniques } & 4.00 & Very High \\
\hline D. 1 & DOST-ESEP ( & & \\
\hline \multicolumn{2}{|c|}{ Instructional Resources } & 4.00 & Very High \\
\hline \multicolumn{2}{|c|}{ Teachers Competencies } & 4.00 & Very High \\
\hline \multicolumn{2}{|c|}{ Evaluation and Grading System } & 4.00 & Very High \\
\hline \multicolumn{2}{|c|}{ Learning Styles and Techniques } & 4.00 & Very High \\
\hline Scale & Description & \multicolumn{2}{|c|}{ Interpretation } \\
\hline $3.51-4.00$ & Very High & \multicolumn{2}{|c|}{ Curriculum are fully implemented } \\
\hline $2.51-3.50$ & High & \multicolumn{2}{|c|}{ Curriculum are highly implemented } \\
\hline $1.51-2.50$ & Low & \multicolumn{2}{|c|}{ Curriculum are slightly implemented } \\
\hline $1.00-1.50$ & Very Low & \multicolumn{2}{|c|}{ Curriculum are not implemented } \\
\hline
\end{tabular}

Evaluation of the support provided by the administration in terms of the implementation of SSP was done among the participating schools. Data show that there is a very high extent of support provided in all schools evaluated at 4.00 (Table 2). The same very high support was further seen in all schools in terms of faculty development, instructional leadership, resources, and rules, policies and admission requirements except for faculty development and resources in Type B school (3.27) (Table 2). This suggests that the administration did not fail in its functions and responsibility to support the teachers, especially in terms of instructional materials needed for the students. Teachers teaching better since 
the support extended by the administration towards them is visible, most especially to their personal and professional development.

The present findings support the ideas of Blasé and Blasé (1999) that formal supportive administrative measures underlie effective classroom situations; Van de Grift and Houtveen (1999) that the weak relationship between leadership and student achievement was due to the influence of their school factors (quality of curriculum, amount of instruction time, attentiveness of pupils, opportunities to learn and capabilities of teachers); and Evans (1998) on a situation exposing the effect of poor management has on teacher morale.

Table 2. Extent of Implementation of Special Science Program (SSP) in Western Visayas along the area of Administrative Support.

\begin{tabular}{|c|c|c|c|c|}
\hline \multicolumn{3}{|l|}{ Type of School } & Mean & Description \\
\hline \multicolumn{3}{|c|}{ A. Entire Group } & 4.00 & Very High \\
\hline \multicolumn{5}{|c|}{ B. Type A Schools - DOST-ESEP (Old) } \\
\hline \multicolumn{3}{|c|}{ Faculty Development } & 4.00 & Very High \\
\hline \multicolumn{3}{|c|}{ Instructional Leadership } & 4.00 & Very High \\
\hline \multirow{2}{*}{\multicolumn{3}{|c|}{$\begin{array}{l}\text { Resources } \\
\text { Rules Policies, and admission }\end{array}$}} & 4.00 & Very High \\
\hline & & & & \\
\hline \multicolumn{3}{|c|}{$\begin{array}{l}\text { Rules, Policies, and admission } \\
\text { Requirement }\end{array}$} & 4.00 & Very High \\
\hline \multicolumn{5}{|c|}{ C. Type B Schools - DOST-ESEP (New) } \\
\hline \multicolumn{3}{|c|}{ Faculty Development } & 3.27 & High \\
\hline \multicolumn{3}{|c|}{ Instructional Leadership } & 4.00 & Very High \\
\hline \multirow{2}{*}{\multicolumn{3}{|c|}{$\begin{array}{l}\text { Resources } \\
\text { Rules, Polici }\end{array}$}} & 3.13 & High \\
\hline & & & & \\
\hline \multicolumn{3}{|c|}{ Requirement } & 4.00 & Very High \\
\hline \multicolumn{5}{|c|}{ D. Type C Schools - Non-DOST-ESEP (Existing) } \\
\hline \multicolumn{3}{|c|}{ Faculty Development } & 4.00 & Very High \\
\hline \multicolumn{3}{|c|}{ Instructional Leadership } & 4.00 & Very High \\
\hline \multirow{2}{*}{\multicolumn{3}{|c|}{$\begin{array}{l}\text { Resources } \\
\text { Rules, Policies, and admission }\end{array}$}} & 4.00 & Very High \\
\hline & & & & \\
\hline \multicolumn{3}{|c|}{ Requirement } & 4.00 & Very High \\
\hline Scale & Description & Interpretation & & \\
\hline $3.51-4.00$ & Very High & Teachers are $f_{l}$ & lly supp & Administrators \\
\hline $2.51-3.50$ & High & Teachers are $\mathrm{h}$ & ghly sur & by Administrators \\
\hline $1.51-2.50$ & Low & Teachers are $\mathrm{s}$ & ghtly su & by administrators \\
\hline $1.00-1.50$ & Very Low & Teachers are $\mathrm{n}$ & t suppo & Administrators \\
\hline
\end{tabular}

\section{Conclusions and Recommendations}

The irregular trends of the NAT-MPS of students among the various Types of SSC indicate the students' mastery of learning concepts, which the teachers facilitate in the transfer of learning. They have the competencies for effective teaching. While they have strengths, they also have needs to be addressed. The teachers'needs that must be enhanced are those related to curriculum, particularly on content, methods and strategies of teaching content and theories and the use and integration of ICT in the classroom. Competencies of the teachers on the application and use of authentic and nontraditional modes of assessment must also be enhanced. In addition, the increasing trend may be due to the sustained support given by the DOST- SEI ESEP and the parents in terms of funding, instructional materials, and facilities. The schools are able to provide SSC students with the latest state- of- the- art facilities that make learning fun and enjoyable. 
Curriculum, instruction, and administrative support influence the performance and achievement of the SSC teachers and the school in general. The relationships between and among the school heads, teachers, and students greatly influence the learning outcomes of the students. The progress of the school and the delivery of the program depend on the concerted efforts of the school personnel and the internal and external stakeholders. In addition, the better the awareness of the teachers, the more open they are to change, the higher the administrative support they receive, the more committed they are, and the better is their teaching performance.

Since the study revealed the irregular trends of the students NAT-MPS performance, teachers should conduct remediation sessions particularly in science and mathematics subjects. Likewise, teachers should be experts in their field of specialization. Library resources should be upgraded and updated by replacing obsolete books and references to further enhance the learning outcomes of the students. Likewise, teachers should develop science inquiry-based process skills in order to make learning more fun and enjoyable. Each school should review its coverage of concepts covered in a year's academic work in class. The DepED should review the SSC curriculum annually or biennially and come up with a list of the revised minimum learning competencies (MLCs) that should be patterned to the call of the K to 12 curriculums.

Support of the school administration, particularly the school principal and heads of the SSC teachers, must be enhanced. The fact that the SSC teachers perform better in teaching the subjects could be attributed to the fact that the principals of the SSC are more supportive, especially in providing the needed materials related for instruction. More direct supervision and response to teachers' problems and concerns, most especially related to the SSC curriculum and instruction performance, may bring better teacher perception of the demands of the curriculum and instruction. Likewise, commitment to and love for the teaching profession must be nurtured in the hearts and minds of the students.

\section{Acknowledgement}

The first author thanks the Department of Science and Technology - Science Education Institute (DOST-SEI) for the dissertation grant.

\section{References}

Astin, A. W., (1993). “What matters in college?" Liberal Education, 79(4), 4-15.

Blasé, J. and Blasé, J., (1999). Principal instructional leadership and teacher development. Teachers Perspective, 35, 349-378.

Calderon, J.F. \& Gonzales, E. (1993). Measurement and evaluation. Manila: National Book Store.

David, A. \& Macayan, J. (2010, July) Assessing Teacher Performance, Retrieved October 23, 2011, from,www.permea.club.officelive.com/Documents/AH_V3_A5.pdf

Evans, C., (1998). The effects senior management teams on teacher morale moral and job satisfaction. Educational Management and Administration, 26, 417-428.

Fuller B. (1987). What school factors raise achievement in the third world? Review of Educational Research, 57 (3), 255-292.

Gray, P. (1990). Science and technology education issues. Impact of science on society, 156, 56-57.

National Association of Secondary Schools Principals, (2009) (NASSP). Retrieved from www.nassp.org/content.aspx?topic $=4702$

Shymansky,J. (1978). Assessing teacher performance in the classroom: Pattern analysis applied to interaction data. Studies in Educational Evaluation, 4(2), 99-106.

Silva, J. \& Ysseldyke J.A. (1998). Assessment (7th Ed.) New York: Houghton Mifflin.

The Glossary of education reforms, 2013 retrieve from http:/ / edglossary.org/assessment/

Van de Grift, W., \& Houtveen, A.A., (1999). Educational leadership and pupil achievement in primary education. School Effectiveness and School Improvement, 10, 373-389.

Yoon, J \& Gilchrist, J (2003). Elementary teacher's perception of administrative support with disruption and aggressive students. Questia, Trusted Online Research. Retrieved September 2011, from www.questia.com/googlescholar.qst?docid=5001928384 http://en.wikipedia.org// wiki/NationalAchievementTest 